\title{
Acceleration of Thrombin-Antithrombin Complex Formation in Rat Hindquarters Via Heparinlike Molecules Bound to the Endothelium
}

\author{
James A. Marcum, James B. McKenney, \\ and Robert D. Rosenberg \\ Department of Biology and the Whitaker College of Health \\ Sciences, Technology, and Management, Massachusetts Institute \\ of Technology, Cambridge, MA 02139; Department of Medicine, \\ Beth Israel Hospital, Boston, MA 02215
}

bstract. We have examined the role of heparinlike molecules in the regulation of coagulation by perfusing rat hindquarters with purified human thrombin and with its plasma inhibitor, antithrombin. Our data indicate that contact of the hemostatic components with the endothelium enhances the rate of thrombin-antithrombin complex formation by as much as 19-fold over the uncatalyzed rate of enzyme-inhibitor interaction. Heparinlike molecules are responsible for the antithrombin accelerating activity. The amount of thrombin-antithrombin complex generated within the hindlimb preparation after pretreatment of the vasculature with purified Flavobacterium heparinase or with addition of platelet Factor IV to the hemostatic components, was equal to the uncatalyzed levels. These heparinlike molecules appear to be tightly bound to the luminal surface of the endothelium, since they could not be detected within the physiologic buffer that was perfused through the animal. The above mucopolysaccharides function in a manner similar to commercial heparin, since modification of antithrombin at a site critical for heparin-dependent acceleration of the protease inhibitor resulted in a level of interaction product identical to the uncatalyzed amount. Finally, addition of diisofluorophosphate-thrombin to the enzyme perfusion stream reduced the amount of thrombin-antithrombin complex formed in the animal by 30 $40 \%$, which suggested that thrombin bound to the en-

Address correspondence to Dr. Rosenberg, Massachusetts Institute of Technology.

Received for publication 27 January 1984 and in revised form 12 April 1984.

J. Clin. Invest.

(c) The American Society for Clinical Investigation, Inc. $0021-9738 / 84 / 08 / 0341 / 10 \quad \$ 1.00$

Volume 74, August 1984, 341-350 dothelium as well as enzyme free in solution are accessible to antithrombin that has interacted with heparinlike molecules present on the endothelium.

\section{Introduction}

In 1973, Damus et al. (1) suggested that the nonthrombogenic properties of blood vessels may be due to the presence of anticoagulantly active heparinlike species on the vascular endothelium. Lollar and Owen (2) demonstrated rapid complexing of radiolabeled thrombin to antithrombin upon injection of the labeled enzyme into the circulation of rabbits. These authors suggested that high affinity thrombin receptors are responsible for this phenomenon. Recently, we have demonstrated that anticoagulantly active heparinlike molecules are intimately associated with microvascular endothelial cells as well as being present within mast cells (3). Based upon the latter data, we have proposed that a small fraction of circulating antithrombin is normally bound to heparinlike species that are located on the luminal side of the vascular endothelium (3). This would permit the protease inhibitor to be selectively activated at bloodsurface interfaces where hemostatic enzymes are commonly generated (4). In the present communication, we provide the first direct evidence that heparinlike substances present on the luminal surface of the vascular endothelium can accelerate thrombin-antithrombin interactions via a mechanism that is identical to that previously described for commercial heparin.

\section{Methods}

Surgery and perfusion system. Male Sprague-Dawley rats (Charles River Breeding Laboratories, Inc., Wilmington, MA) weighing $\sim 250-350 \mathrm{~g}$ were anesthetized with intraperitoneal injections of Nembutal (50 $\mathrm{mg} / \mathrm{kg}$ ) and placed in a supine position on a dissecting board. Isolation of the hindquarters was performed according to a modification of the procedure of Ruderman et al. (5). Toward this end, the abdomen was opened by midline and transverse incisions. The iliolumbar, inferior mesenteric, inferior epigastric, hypogastric, and spermatic arteries and veins were ligated with surgical silk. The descending colon proximal to and distal to the ligated inferior mesenteric artery and vein was also 
ligated. This segment of the colon as well as the testicles were removed, and a ligature was placed around the tail. The dorsal aorta and posterior vena cava were cannulated below the renal arteries with a 19-gauge Intracath cannula (Desert Co., Sonsy, VT) and a 14-gauge Quick-Cath cannula (Baxter Travenol Laboratories, Deerfield, IL), respectively.

Perfusion of the hindlimb vasculature in situ with modified KrebsHenseleit buffer (5), (118 mM NaCl, $4.7 \mathrm{mM} \mathrm{KCl}, 3.0 \mathrm{mM} \mathrm{CaCl}, 1.2$ $\mathrm{mM} \mathrm{KH}_{2} \mathrm{PO}_{4}, 25 \mathrm{mM} \mathrm{NaHCO} 3$ ) containing $1-5 \mathrm{mg} / \mathrm{ml}$ of bovine serum albumin (Fraction V, Sigma Chemical Co., St. Louis, MO), pH 7.4 (KH buffer),' was immediately initiated at a flow rate of $15-20 \mathrm{ml} / \mathrm{min}$ and at a perfusion pressure of $60-80 \mathrm{~mm} \mathrm{Hg}$. The $\mathrm{KH}$ buffer was equilibrated for $\sim 30$ min with a gas mixture of $95 \% \mathrm{O}_{2}$ and $5 \% \mathrm{CO}_{2}$ at a flow rate of $1-21 / \mathrm{min}$, before use. A peristaltic pump (WatsonMarlow, England) was employed to transfer the above buffer from the reservoir to the aorta. The blood was flushed from the hindquarters with $50-100 \mathrm{ml}$ of the $\mathrm{KH}$ buffer before perfusion of the hemostatic components. Coagulation proteins (see below) were perfused through the aorta with either an infusion pump or a peristaltic pump, or were injected into the perfusion stream with a syringe. A single pass through the hindlimb preparation required $\sim 20 \mathrm{~s}$, as determined by injection of ${ }^{125}$ I-labeled bovine serum albumin into the $\mathrm{KH}$ buffer perfusion stream. All studies were conducted at $24^{\circ} \mathrm{C}$.

Preparation and quantitation of proteins. Human thrombin was isolated from plasma according to an established procedure (6). The final product had a specific activity of 2,500 National Institutes of Health $\mathrm{U} / \mathrm{mg}$ and exhibited a single band on polyacrylamide gel electrophoresis. Occasionally, the purified enzyme was treated with two successive additions of a $100 \mathrm{M}$ excess of diisopropylfluorophosphate (Sigma Chemical Co.). The absence of significant proteolytic activity was documented by using a specific chromogenic assay that employed the substrate Tos-Gly-Pro-Arg-pNA AcOH (Chromozym TH, Boehringer Mannheim Biochemicals, Indianapolis, IN). The amount of free thrombin within the above preparation was estimated by adding an excess of antithrombin and by using a specific radioimmunoassay for the thrombin-antithrombin complex (see below). In all cases, the levels of active enzyme were $<1 \%$ of that within the initial sample.

Antithrombin was purified from human plasma according to methods previously reported (6). This material was homogeneous as judged by SDS and polyacrylamide gel electrophoresis. In certain instances, the protease inhibitor was modified with dimethyl (2-hydroxy-5-nitrobenzyl) sulfonium bromide according to the method of Blackburn and Sibley (7). Approximately $1.3 \mathrm{~mol}$ of the reagent was incorporated per mole of the protease inhibitor. Hirudin was prepared from leech extract (Pentapharm, Basel, Switzerland) according to a method outlined in a prior publication (6). The final product was judged homogeneous by polyacrylamide gel electrophoresis and was able to neutralize 11,000 National Institutes of Health units of thrombin per mg of hirudin. Purified human platelet factor four $\left(\mathrm{PF}_{4}\right)$ was a generous gift of Dr. Henry Slayter, DanaFarber Cancer Institute, Boston, MA. The protein was physically homogeneous, as judged by SDS gel electrophoresis, and yielded a molar stoichiometry of $0.85-1.0$ when titrated with highly active heparin (8).

Flavobacterium heparina, provided by Dr. R. Langer, Massachusetts Institute of Technology, Boston, MA, were sonicated, and nucleic acids were precipitated with ammonium sulfate (9). After centrifugation, the

1. Abbreviations used in this paper: DIP-thrombin, diisofluorophosphatethrombin; KH buffer, modified Krebs-Henseleit buffer $(118 \mathrm{mM} \mathrm{NaCl}$, $4.7 \mathrm{mM} \mathrm{KCl}, 3.0 \mathrm{mM} \mathrm{CaCl}, 1.2 \mathrm{mM} \mathrm{KH}_{2} \mathrm{PO}_{4}, 25 \mathrm{mM} \mathrm{NaHCO}$ ) containing $1-5 \mathrm{mg} / \mathrm{ml}$ of bovine serum albumin (Fraction $\mathrm{V}$, Sigma Chemical Co.), $\mathrm{pH}$ 7.4; $\mathrm{PF}_{4}$, purified human platelet factor 4 . supernate that contained the crude enzyme preparation was chromatographed on columns of hydroxylapatite, cellulose-phosphate, and Sephacryl S-200 according to methods previously published from our laboratory (10). The semipurified enzyme preparation was then applied to a column of polybuffer exchanger chromatofocusing gel (Pharmacia Fine Chemicals, Piscataway, NJ), and the bacterial enzyme was eluted with Polybuffer $96-\mathrm{HCl}$, pH 7.0 (Pharmacia Fine Chemicals) at an average isoelectric point of 8.65. The final product was homogeneous as judged by nonequilibrium $\mathrm{pH}$ gradient (pH 3.5-10) electrophoresis using $4 \%$ acrylamide gels that contained $8 \mathrm{M}$ urea (11). The heparin-cleaving activity of the purified bacterial enzyme was $3,650 \mathrm{U} / \mathrm{mg}$ as determined by Azure A hyperchromicity (12). Analysis of the purified mucopolysaccharidase $(10 \mu \mathrm{g})$ revealed no significant proteolytic activity, as quantitated by hydrolysis of ${ }^{125} \mathrm{I}$-labeled alpha casein for $10 \mathrm{~min}$ at $37^{\circ} \mathrm{C}$ with estimation of perchloric acid-soluble radiolabeled peptides (13). Approximately $100 \mathrm{ng}$ of protease activity can be detected with the radioisotopic caseinolytic assay. Chondroitinase activity was not observable in the purified bacterial enzyme preparation (20 U), as measured by degradation of chondroitin 4-S and 6-S or dermatan sulfate for $4 \mathrm{~h}$ at $37^{\circ} \mathrm{C}(14)$. Samples were obtained before as well as immediately after treatment with the purified bacterial enzyme and were filtered through columns of Sephadex G-25. Degradation of the mucopolysaccharides was ascertained by comparing the levels of complex carbohydrate present in the excluded volume of the column (polysaccharide) vis-á-vis those located in the included volume of the column (oligosaccharide). Less than $0.1 \mathrm{U}$ of chondroitin $\mathrm{ABC}$ lyase could be detected under the above assay conditions.

Protein concentrations were quantitated by absorbance measurements at $280 \mathrm{~nm}$ using appropriate extinction coefficients (6) or by the procedure of Lowry et al. (15).

Assay procedures. The concentration of thrombin-antithrombin complex was quantitated by a minor modification of the double antibody radioimmunoassay described by Lau and Rosenberg (16). Results obtained in our experiments were compared with a standard curve which was constructed with purified thrombin-antithrombin complex ranging in concentration from 0.4 to $12.9 \mathrm{nM}$ and with added antithrombin at levels used during perfusion. The protease inhibitor was added to the standard curve to account for a small nonspecific effect of this protein upon the radioimmunoassay for the interaction product within a nonplasma system.

The concentration of antithrombin was estimated with a double antibody radioimmunoassay according to the procedure of Bauer et al. (17). Results obtained were compared with a standard curve which was constructed with the purified protease inhibitor ranging in concentration from 0.15 to $5.0 \mathrm{nM}$. Measurement of $\mathrm{PF}_{4}$ was performed utilizing a specific radioimmunoassay kit for this component (Abbott Laboratories, North Chicago, IL). Dose-response curves for the radioimmunoassays were constructed by using a computer-assisted least squares fit of the raw data to the four parameter model of Rodbard et al. $(18,19)$. Statistical analyses were conducted by standard techniques (20).

Kinetic evaluation of thrombin-antithrombin interaction. The second order rate constant for the thrombin-antithrombin interaction was determined by quantitating the residual level of enzymatic activity as a function of the time of incubation with protease inhibitor according to the method of Jordan et al. (21). Environmental conditions were $\mathrm{KH}$ buffer at $24^{\circ} \mathrm{C}$ or $0.15 \mathrm{M} \mathrm{NaCl}$ in $0.01 \mathrm{M}$ Tris- $\mathrm{HCl}, \mathrm{pH} 7.5$ at $37^{\circ} \mathrm{C}$.

Histological examination. The vasculature was fixed by perfusing $2.0 \%$ paraformaldehyde, $2.5 \%$ gluteraldehyde, and $0.025 \% \mathrm{CaCl}_{2}$ in 0.1 $\mathrm{M}$ sodium cacodylate buffer, $\mathrm{pH} 7.4$, through the hindquarters for $1 \mathrm{~h}$ at $24^{\circ} \mathrm{C}$. Hindlimb muscle samples were excised from animals and were 
placed in the above solution for an additional $5-10 \mathrm{~min}$ at $24^{\circ} \mathrm{C}$. The tissue was trimmed so that the thickness of one side did not exceed 2 $\mathrm{mm}$. Tissue was postfixed in osmium tetroxide, and $1 \mu \mathrm{m}$ thick Eponembedded sections were prepared. Sections were stained for $1 \mathrm{~h}$ in Giemsa diluted 1:10 in $0.05 \mathrm{M}$ acetate buffer, $\mathrm{pH} 4-6$, according to the procedure of Dvorak et al. (22).

The number of capillaries perfused with $\mathrm{KH}$ buffer during the above experiments was estimated by a modification of the ink perfusion technique of Renkin et al. (23). Thus, 1-2 ml of Indian ink (Faber Castell, Newark, NJ) was dialyzed against $\mathrm{KH}$ buffer without added bovine serum albumin and was injected into the physiologic buffer perfusion stream. Tissue samples were removed from hindlimb muscles and were immediately frozen. Paired serial sections $(12 \mu \mathrm{m}$ thick) were either counterstained with eosin to show ink-filled microvessels or reacted for alkaline phosphatase activity to show total number of vessels. Microvessels $(<12 \mu \mathrm{m}$ in diameter) were counted using a Nikon microscope with an objective magnification of $\times 40$. The fraction of perfused microvessels was computed by dividing the number of ink-filled vessels from the field of an eosin-stained section by the number of vessels from the corresponding field of the alkaline phosphatase-reacted section.

\section{Results}

The rat hindlimb vasculature was perfused with $\mathrm{KH}$ buffer that contained purified human thrombin $(5.4 \mathrm{nM})$ via the dorsal systemic aorta (see Methods). Light microscopic examination of the muscle vasculature before, and immediately after, perfusion of the hindlimb preparation revealed that the endothelial layer was undamaged and that blood vessels were intact. The number of capillaries perfused within the musculature was estimated by infusion of Indian ink into the $\mathrm{KH}$ buffer perfusion stream (23). Under the conditions of our experiments, $23.2 \pm 4.3 \%$ (SE) $(n=9)$ of the capillaries were perfused.

To initiate our studies, $\mathrm{KH}$ buffer that contained thrombin ( $5.4 \mathrm{nM}$ ) was perfused through the hindquarters until the concentration of free enzyme within the vascular system achieved a steady state level (see below). The initial perfusion of thrombin, rather than antithrombin, was required to saturate nonspecific sites on the cannuli, to which the protease binds. At this point, purified human antithrombin was infused through the vasculature at constant levels that ranged from 0.03 to $1.79 \mu \mathrm{M}$ or injected into the perfusion stream as a $0.5-\mathrm{ml}$ bolus $(2.7 \mathrm{nmol})$. The effluent from the vena cava was collected as 1-ml fractions (final volume) into polystyrene tubes that contained either 100 $\mu l$ of $0.154 \mathrm{M} \mathrm{NaCl}$ with $25 \mathrm{U} / \mathrm{ml}$ of purified hirudin, or 100 $\mu l$ of $0.154 \mathrm{M} \mathrm{NaCl}$ with antithrombin $(18 \mathrm{nM})$. Hirudin was employed in tubes 2-5 (constant infusion) or 2-7 (bolus injection) to rapidly neutralize thrombin and to prevent further formation of the enzyme-inhibitor complex once the components had exited the hindquarters. The amount of the enzyme-inhibitor complex generated within the hindlimb preparation during perfusion of the hemostatic components was measured with a specific radioimmunoassay for the interaction product. Antithrombin was utilized in tubes 1 and 6 (constant infusion) or 1 and 8 (bolus injection) to bind thrombin and to permit the concentration of free enzyme to be indirectly estimated via the resultant level of thrombin-antithrombin complex.
The free thrombin and antithrombin that exited the hindlimb preparation during studies employing constant infusion of the protease inhibitor averaged $64.4 \pm 3.8(\mathrm{SE})$ and $93.3 \pm 7.5 \%(\mathrm{SE})$, respectively, of the initial levels of the coagulation proteins perfused through the rat hindquarters. The free thrombin and antithrombin that emerged from the hindlimbs during experiments using bolus injection of the protease inhibitor averaged $54.9 \pm 2.3$ (SE) and $42.4 \pm 3.9 \%$ (SE), respectively, of the starting amounts of the hemostatic components perfused through the hindlimb preparation. The decreased levels of free enzyme that exited the hindquarters during our studies were shown by additional experiments to be caused by nonspecific adsorption of this protein to plastic containers and tubing before infusion into the hindquarters (data not shown). In a similar fashion, the reduced amounts of antithrombin that emerged from the hindquarters during bolus injection of the protease inhibitor was also caused by retention of the protein on the plastic tubing and vessel cannuli.

Initially, the quantities of thrombin-antithrombin complex generated within the hindlimb circuit-consisting of the animal and the aortic as well as vena caval cannuli-were determined by perfusing constant levels of thrombin ( $5.4 \mathrm{nM})$ and antithrombin $(0.09 \mu \mathrm{M})$ through the hindlimb preparation. The amounts of the interaction product formed within the aortic and vena caval cannuli were quantitated by perfusing identical concentrations of thrombin and antithrombin through these elements as outlined for the hindquarters. The levels of enzymeinhibitor complex generated during the 20 -s period of residence of hemostatic components within the vasculature of the animal were calculated by subtracting the amounts of interaction product produced within the vessel cannuli from that formed within the hindlimb circuit. The data shown in Fig. 1 represents averaged values obtained from two animals. The amounts of enzyme-inhibitor complex formed within the vasculature should be contrasted with the uncatalyzed levels of interaction product that would be produced within a comparable time interval in $\mathrm{KH}$ buffer at $24^{\circ} \mathrm{C}$ in the absence of heparin. The latter value was calculated from the concentrations of the hemostatic components emerging from the hindlimb circuit, and the experimentally determined estimates of the bimolecular rate constant of this interaction were obtained under the above conditions of solvent and temperature $\left(4.39 \times 10^{5} \mathrm{M}^{-1} \mathrm{~min}^{-1} \pm 0.28 \times 10^{5}\right.$ $\left.\mathrm{M}^{-1} \mathrm{~min}^{-1}(\mathrm{SE}), n=5\right)$. It is readily apparent that the rate of thrombin inactivation via antithrombin within the perfused hindquarters is enhanced $\sim 12$-fold over the uncatalyzed rate of enzyme-inhibitor complex formation.

Subsequently, a series of experiments identical to those described above were conducted in which human antithrombin was infused at final concentrations ranging from 0.03 to 1.79 $\mu \mathrm{M}$ into the thrombin perfusion stream. The data provided in Table I were computed by averaging four separate observation points from each hindlimb circuit (Fig. 1) and subtracting the amounts of interaction product formed within the vessel cannuli, as outlined above. At concentrations of antithrombin that ranged 


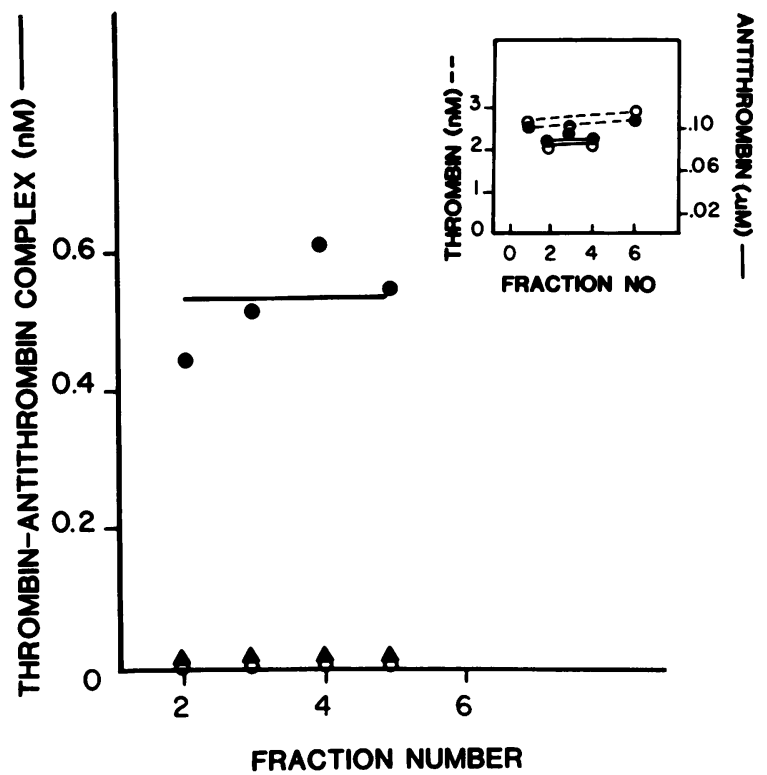

Figure 1. $\mathrm{KH}$ buffer that contained thrombin $(5.4 \mathrm{nM})$ was perfused through the rat hindlimb preparation, and either native or modified antithrombin was infused at $0.09 \mu \mathrm{M}$. The amounts of thrombin-antithrombin complex $(\bullet-\bullet)$ and thrombin-modified antithrombin complex $(0-0)$ were measured by specific radioimmunoassay and plotted as the mean of two separate experiments. The uncatalyzed amount of the enzyme-inhibitor complex ( $\Delta-\Delta)$ was computed from the concentration of the coagulation proteins employed and the bimolecular rate constant for the interaction product in the absence of heparin. The inset depicts the average levels of free thrombin before and immediately after emergence of native antithrombin $(\bullet---\bullet)$ and modified antithrombin $(0---0)$ from the hindquarters, as well as the average levels of native antithrombin ( $\bullet \bullet)$ and modified antithrombin $(\mathrm{O}-\mathrm{O})$ exiting the hindlimb preparation.

from 0.03 to $0.18 \mu \mathrm{M}$, the rates of thrombin neutralization by antithrombin were accelerated $\sim 11-19$-fold over the uncatalyzed levels of enzyme-inhibitor complex formation. However, at the highest level of protease inhibitor $(1.97 \mu \mathrm{M})$ used in our experiments, the rate of enzyme inactivation by antithrombin was only fourfold greater than the uncatalyzed rate (data not shown).

The extent of acceleration of thrombin-antithrombin interactions within the hindquarters was also examined by injecting a $0.5-\mathrm{ml}$ bolus of the protease inhibitor $(2.7 \mathrm{nmol})$ into the enzyme perfusion stream. The recovery of the thrombin-antithrombin complex was estimated by adding the protease inhibitor to the enzyme at final concentrations of $5.4 \mu \mathrm{M}$ and 5.4 $\mathrm{nM}$, respectively, individually perfusing the resultant interaction product through the hindlimb preparation, and assaying the effluents for the presence of this component. The recovery of the thrombin-antithrombin complex averaged $49 \pm 6.4 \%$ (SE) ( $n$ $=8$ ). This value was used to calculate the amounts of enzymeinhibitor complex that were generated within the hindlimb cir-
Table I. Generation of Thrombin-Antithrombin Complex during Constant Infusion of Native or Modified Antithrombin

\begin{tabular}{|c|c|c|c|c|c|}
\hline \multirow{4}{*}{$\begin{array}{l}\text { Anti- } \\
\text { thrombin } \\
\text { infused }\end{array}$} & \multicolumn{3}{|c|}{ Thrombin-antithrombin complex (pmol/20 s) } & \multirow{2}{*}{\multicolumn{2}{|c|}{ Acceleration }} \\
\hline & \multicolumn{2}{|l|}{ Animal* } & \multirow{3}{*}{$\begin{array}{l}\text { Un- } \\
\text { catalyzed }\end{array}$} & & \\
\hline & \multicolumn{2}{|l|}{ Antithrombin } & & \multicolumn{2}{|c|}{ Antithrombin } \\
\hline & Native & Modified & & Native & Modified \\
\hline \multicolumn{6}{|l|}{$m M$} \\
\hline 0.03 & $0.26 \pm 0.1 \quad(n=3)$ & $\mathrm{ND} \ddagger(n=2)$ & 0.014 & 18.6 & - \\
\hline 0.09 & $0.48 \pm 0.12(n=6)$ & $\mathrm{ND} \ddagger(n=5)$ & 0.043 & 11.2 & - \\
\hline 0.18 & $0.94 \pm 0.17(n=13)$ & $0.22 \pm 0.04(n=4)$ & 0.086 & 10.9 & 2.6 \\
\hline
\end{tabular}

* Mean \pm SE. Enzyme-inhibitor complex formation within the cannuli at antithrombin concentrations of $0.03,0.09$, and $0.18 \mu \mathrm{M}$ were $0.154 \pm 0.46(n=2)$, $0.26 \pm 0.18(n=5)$, and $0.283 \pm 0.59(n=5) \mathrm{pmol} / 20 \mathrm{~s}$, respectively. These values were subtracted from the original data to obtain the amount of complex generated within $20 \mathrm{~s}$ in the vasculature of the animal. $¥ N D$, not detected.

cuit, assuming complete recovery of the interaction product. The levels of enzyme-inhibitor complex formed within the vessel cannuli during injection of antithrombin were determined in a fashion identical to that described for the hindlimb circuit. The recovery of enzyme-inhibitor complex from the vessel cannuli was quantitated as outlined above and averaged $78 \pm 3.6 \%$ (SE) $(n=6)$. This value was used to compute the levels of interaction product produced within the vessel cannuli during the perfusion studies. The amounts of the enzyme-inhibitor complex generated during the 20-s period of residence of the hemostatic components within the vasculature of the animal were determined by subtracting the levels of interaction product formed within the vessel cannuli from the quantities of thrombin-antithrombin complex produced within the hindlimb circuit, assuming a complete recovery of this component. The data provided in Fig. 2 represents the mean of two animals. The amounts of enzyme-inhibitor complex generated within the vasculature should be contrasted with the uncatalyzed level of the interaction product that would be produced within a comparable time interval under identical conditions of solvent and temperature. The data indicate that the rate of thrombin neutralization by antithrombin within the hindlimb preparation was enhanced threefold over the uncatalyzed rate.

Thereafter, a series of experiments similar to those described above were conducted, in which antithrombin was injected as a $0.5-\mathrm{ml}$ bolus $(2.7 \mathrm{nmol})$ into the thrombin perfusion stream. The amounts of enzyme-inhibitor complex were determined by summing the three peak fractions in each experiment (see Fig. 2). The data in Table II represent the amounts of thrombinantithrombin complex generated in the hindlimb circuit less that formed within the vessel cannuli, assuming complete recovery of the interaction product. The results demonstrate that the rate of the thrombin-antithrombin complex formation is 


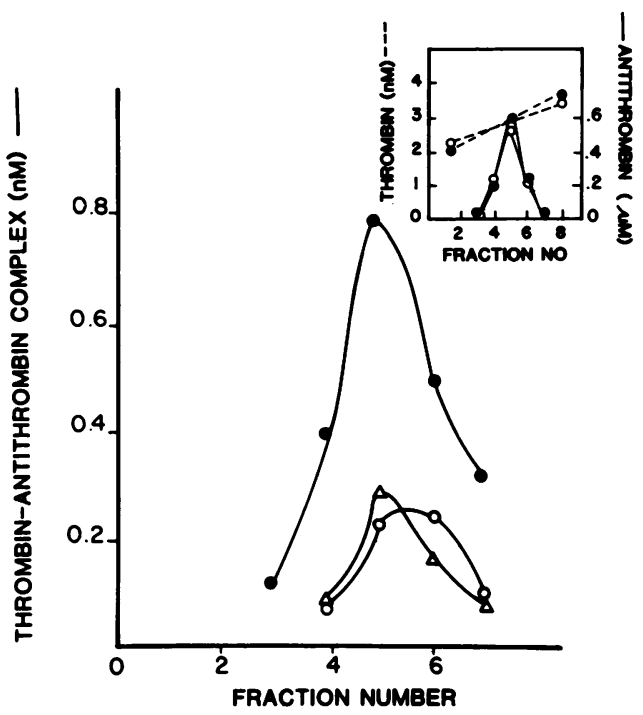

Figure 2. KH buffer that contained thrombin ( $5.4 \mathrm{nM})$ was perfused through the rat hindlimb preparation and a $0.5-\mathrm{ml}$ bolus of either native or modified antithrombin $(2.7 \mathrm{nmol})$ was injected into the perfusion stream. The amounts of thrombin-antithrombin complex $(\bullet-\bullet)$ and thrombin-modified antithrombin complex $(0-0)$ were measured by specific radioimmunoassay and plotted as the mean of two separate experiments. The uncatalyzed amounts of the enzyme-inhibitor complex $(\Delta-\Delta)$ were calculated from the concentration of hemostatic components used and the bimolecular rate constant for the interaction product in the absence of heparin. The inset depicts the average levels of free thrombin before and immediately after the emergence of native antithrombin ( $\bullet---\bullet)$ and modified antithrombin $(\mathrm{O}---\mathrm{O})$ from the hindlimb preparation, as well as the average levels of native antithrombin $(\bullet-\bullet)$ and modified antithrombin $(\mathrm{O}-\mathrm{O})$ exiting the hindlimb preparation.

accelerated fourfold over the uncatalyzed rate of enzyme-inhibitor interaction (Table II).

To determine whether the antithrombin-accelerating activity observed in the above experiments was due to a heparinlike species within the hindlimb preparation, purified Flavobacterium heparinase was added to $\mathrm{KH}$ buffer at a final concentration of $160 \mathrm{ng} / \mathrm{ml}$ and circulated through the hindquarters for $10 \mathrm{~min}$ at $24^{\circ} \mathrm{C}$. Purified human thrombin and antithrombin at final concentrations of $5.4 \mathrm{nM}$ and $0.18 \mu \mathrm{M}$, respectively, were then perfused through the hindlimb preparation as outlined previously, and the amounts of enzyme-inhibitor complex generated within the vasculature were determined by a specific radioimmunoassay for the interaction product. Under these conditions, the rate of thrombin-antithrombin complex formation was reduced to the uncatalyzed rate of enzyme-inhibitor interaction (Table III). The recirculation of $\mathrm{KH}$ buffer without added purified bacterial enzyme for $10 \mathrm{~min}$ at $24^{\circ} \mathrm{C}$ did not alter the amounts of enzyme-inhibitor complex generated within the vasculature of the animal (1.09 pmol/20 s $\pm 0.18 \mathrm{pmol} / 20 \mathrm{~s}(\mathrm{SE}), n=4)$.

To evaluate whether $\mathrm{PF}_{4}$ could modulate the above acceleratory phenomenon, purified human $\mathrm{PF}_{4}(3.3 \mathrm{nmol})$ was added
Table II. Generation of Thrombin-Antithrombin Complex during Bolus Injection of Antithrombin

\begin{tabular}{|c|c|c|}
\hline $\begin{array}{l}\text { Proteins perfused through } \\
\text { hindlimb preparation }\end{array}$ & $\begin{array}{l}\text { Thrombin-antithrombin } \\
\text { complex* (pmol/20 s) }\end{array}$ & $\begin{array}{l}\text { Acceler- } \\
\text { ation }\end{array}$ \\
\hline \multicolumn{3}{|l|}{$\begin{array}{l}\text { Thrombin }(5.4 \mathrm{nM}) \text { followed } \\
\text { by native antithrombin }\end{array}$} \\
\hline$(2.7 \mathrm{nmol})$ & $2.06 \pm 0.19(n=16)$ & 4.2 \\
\hline \multicolumn{3}{|l|}{$\begin{array}{l}\text { Thrombin }(5.4 \mathrm{nM}) \text { followed } \\
\text { by modified antithrombin }\end{array}$} \\
\hline (2.7 nmol) & $0.53 \pm 0.07(n=9)$ & 1.1 \\
\hline \multicolumn{3}{|l|}{$\begin{array}{l}\text { Thrombin }(5.4 \mathrm{nM}) \text { followed } \\
\text { by native antithrombin } \\
(2.7 \mathrm{nmol})+\mathrm{PF}_{4}\end{array}$} \\
\hline (3.3 nmol) & $0.55 \pm 0.11(n=5)$ & 1.1 \\
\hline \multicolumn{3}{|l|}{$\begin{array}{l}\text { Thrombin }(5.4 \mathrm{nM})+\text { DIP- } \\
\text { thrombin }(27 \mathrm{nM}) \\
\text { followed by native }\end{array}$} \\
\hline antithrombin $(2.7 \mathrm{nmol})$ & $1.45 \pm 0.24(n=8)$ & 3.0 \\
\hline Uncatalyzed amount & 0.49 & \\
\hline
\end{tabular}

* Mean \pm SE. Enzyme-inhibitor complex formation within the cannuli was $1.43 \pm 0.03(n=15) \mathrm{pmol} / 20 \mathrm{~s}$. This value was subtracted from the original data to obtain the amount of complex generated within $20 \mathrm{~s}$ in the vasculature of the animal.

to the antithrombin bolus $(2.7 \mathrm{nmol})$ before injection into enzyme perfusion stream. The amounts of thrombin-antithrombin complex emerging from the hindquarters were quantitated, and the levels of enzyme-inhibitor interaction product formed within the aortic and venal caval cannuli were subtracted. Then, the previously cited recoveries of this component were used to calculate the quantities of the thrombin-antithrombin complex generated within the vasculature of the animal in the presence of $\mathrm{PF}_{4}$, assuming complete recovery of the interaction product. The averaged data is presented in Table II and reveals that the

Table III. Generation of Thrombin-Antithrombin Complex during Constant Infusion of Antithrombin

\begin{tabular}{|c|c|}
\hline Proteins perfused through hindlimb preparation & $\begin{array}{l}\text { Thrombin-antithrombin } \\
\text { complex }{ }^{*}(\mathrm{pmol} / 20 \mathrm{~s})\end{array}$ \\
\hline $\begin{array}{l}\text { Thrombin ( } 5.4 \mathrm{nM}) \text { followed by native } \\
\text { antithrombin }(0.18 \mu \mathrm{M})\end{array}$ & $0.94 \pm 0.17 \quad(n=13)$ \\
\hline $\begin{array}{l}\text { Thrombin }(5.4 \mathrm{nM})+\text { DIP-thrombin } \\
(27 \mathrm{nM}) \text { followed by native } \\
\text { antithrombin }(0.18 \mu \mathrm{M})\end{array}$ & $0.55 \pm 0.12 \quad(n=5)$ \\
\hline $\begin{array}{l}\text { Thrombin ( } 5.4 \mathrm{nM}) \text { after treatment } \\
\text { with purified heparinase followed by } \\
\text { native antithrombin }(0.18 \mu \mathrm{M})\end{array}$ & $0.074 \pm 0.013(n=4)$ \\
\hline Uncatalyzed amount & 0.086 \\
\hline
\end{tabular}

* Mean \pm SE. See legend to Table I for additional details. 
addition of $\mathrm{PF}_{4}$ to antithrombin was responsible for a decrease in the rate of enzyme-inhibitor complex formation to the uncatalyzed rate. It should be noted that $\mathrm{PF}_{4}$ had no effect upon the radioimmunoassay for thrombin-antithrombin complex at the concentrations used, and that $\sim 98 \%$ of the injected $\mathrm{PF}_{4}$ was trapped within the hindquarters, as judged by a specific radioimmunoassay for this component.

To ascertain whether the anticoagulantly active heparinlike molecules detected in the above experiments were tightly associated with vascular elements, thrombin was perfused through the hindlimb preparation as described earlier, antithrombin (2.7 $\mathrm{nmol}$ ) was added at varying times to the emerging fluid phase or to an appropriate buffer control, and the extent of enzymeinhibitor interaction was determined over a 30 -s period of time by specific radioimmunoassay. These studies revealed that the rates of thrombin-antithrombin complex formation within the perfusate and the buffer control were identical (data not shown).

To demonstrate whether the heparinlike species present within the hindlimb vasculature activated antithrombin in a manner similar to commercial heparin, purified human antithrombin was chemically modified at the tryptophan 49 residue and was infused or injected into the hindquarters during thrombin perfusion. The altered protease inhibitor interacts with thrombin at a normal rate in the absence of heparin, whereas the rate of enzyme neutralization is only minimally augmented in the presence of this mucopolysaccharide. In the absence of heparin, the bimolecular rate constants of native and modified antithrombin are $6.6 \times 10^{5} \mathrm{M}^{-1} \mathrm{~min}^{-1} \pm 1.8 \times 10^{5} \mathrm{M}^{-1} \mathrm{~min}^{-1}$ (SE) $(n=3)$ and $5.5 \times 10^{5} \mathrm{M}^{-1} \mathrm{~min}^{-1} \pm 1.9 \times 10^{5} \mathrm{M}^{-1} \mathrm{~min}^{-1}$ (SE) $(n=3)$, respectively. However, in the presence of saturating levels of the anticoagulant, the bimolecular rate constants for native and modified antithrombin are $5.6 \times 10^{8} \mathrm{M}^{-1} \mathrm{~min}^{-1} \pm 0.9$ $\times 10^{8} \mathrm{M}^{-1} \min ^{-1}(\mathrm{SE})(n=2)$ and $9.1 \times 10^{5} \mathrm{M}^{-1} \min ^{-1} \pm 1.0$ $\times 10^{5} \mathrm{M}^{-1} \min ^{-1}(\mathrm{SE})(n=3)$, respectively. The above kinetic constants were determined at an environmental temperature of $37^{\circ} \mathrm{C}$. It should also be noted that the native and modified antithrombin exhibited identical immunoreactivities when present as free inhibitor or complexed with thrombin (data not shown).

The amounts of thrombin-modified antithrombin complex generated within the hindlimb preparation including vessel cannuli were determined by perfusing constant levels of the enzyme $(5.4 \mathrm{nM})$ and tryptophan-modified protease inhibitor $(0.09 \mu \mathrm{M})$ through the hindlimb circuit. The levels of thrombin-modified antithrombin complex produced within the aortic and vena caval cannuli were estimated in a fashion similar to that outlined above, and the quantities of enzyme-modified inhibitor complex generated within the animal were calculated as previously described. Fig. 1 depicts the averaged data obtained from two animals. Our findings indicate that the rate of thrombin-modified antithrombin complex formation within the hindquarters is equal to the uncatalyzed rate of enzyme-inhibitor interaction. Similar results were obtained when modified antithrombin was injected as a $0.5-\mathrm{ml}$ bolus $(2.7 \mathrm{nmol})$ into the thrombin perfusion stream (Fig. 2). These differences were observed despite similar levels of free thrombin and native or modified antithrombin present within the vascular tree (see insets to Figs. 1 and 2).

A series of experiments similar to those described above were conducted in which tryptophan-modified antithrombin was infused at constant levels ranging from 0.03 to $0.18 \mu \mathrm{M}$ into the thrombin perfusion stream. The amounts of enzymemodified inhibitor complex generated within the vascular system of the animal were computed as outlined previously. When the modified protein was employed at low concentrations $(0.03$ and $0.09 \mu \mathrm{M})$, the rate of the thrombin-modified antithrombin complex generated within the hindlimb preparation was similar to the uncatalyzed rate of enzyme-inhibitor interaction (Table I). Infusion of a higher level of modified antithrombin $(0.18 \mu \mathrm{M})$ resulted in a slight enhancement in the rate of enzyme-modified inhibitor complex formation when compared with the uncatalyzed rate of this interaction (Table I).

Thereafter, studies were undertaken in which tryptophanmodified antithrombin was injected as a $0.5-\mathrm{ml}$ bolus $(2.7 \mathrm{nmol})$ during thrombin perfusion. The recoveries of enzyme-inhibitor complex within the hindlimb circuit and the vessel cannuli were quantitated as described previously and averaged $49 \pm 6.4$ (SE) $(n=8)$ and $81 \pm 5.8 \%$ (SE) $(n=6)$, respectively. These values were employed to compute the average quantities of thrombinmodified antithrombin complex generated within the hindlimb circuit and vessel cannuli, respectively, assuming complete recovery of the interaction product. The average amounts of thrombin-modified antithrombin complex formed during the 20-s period of residence of the hemostatic components within the vasculature of the animal, assuming complete recovery of the interaction product, were calculated as previously described. The data provided in Table II indicates that the rate of thrombin neutralization by modified antithrombin is similar to the uncatalyzed rate of enzyme-inhibitor interaction.

Thrombin has been shown to interact with sites on cultured endothelial cells as well as with vessel wall endothelium $(2,24)$. We examined the possibility that the enzyme is bound to the luminal surface of the endothelium during perfusion through the hindquarters. $\mathrm{KH}$ buffer that contained purified human thrombin $(5.4 \mathrm{nM})$ and $1,000 \mathrm{cpm} / \mathrm{ml}$ of ${ }^{125} \mathrm{I}$-labeled bovine serum albumin was perfused through the hindlimb preparation. Enzyme concentrations were measured by using an amidolytic assay (14). The latter assay, in contrast to the radioimmunoassay for thrombin-antithrombin complex, measured the enzymatic activity of thrombin. Approximately $13 \mathrm{ml}$ of the KH buffer that contained thrombin must be perfused through the hindlimb preparation before a steady state level of the enzyme is attained (Fig. 3). This result should be compared with data simultaneously obtained with ${ }^{125} \mathrm{I}$-labeled bovine serum albumin, which indicates that steady state levels of this component were reached after $\sim 7 \mathrm{ml}$ of the $\mathrm{KH}$ buffer that contained the radiolabeled protein had been perfused through the above preparation (Fig. 3 ). When $\mathrm{KH}$ buffer that contained thrombin ( $5.4 \mathrm{nM})$ and DIP-thrombin (27 $\mathrm{nM}$ ) were perfused through the hindquarters, the enzyme 
Figure 3. KH buffer that contained thrombin $(5.4$

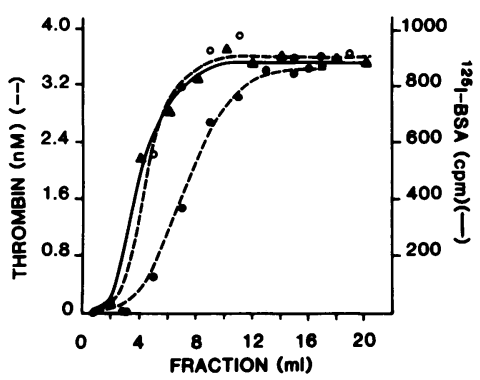

nM) $(\bullet---\bullet)$ and 1,000 $\mathrm{cpm} / \mathrm{ml}$ of ${ }^{125}$ I-labeled bovine serum albumin $(\Delta-\Delta)$ or thrombin $(5.4$ $\mathrm{nM})$ and DIP-thrombin (27 nM) $(0---0)$ and 1,000 $\mathrm{cpm} / \mathrm{ml}$ of ${ }^{125} \mathrm{I}$-labeled bovine serum albumin $(\Delta-\Delta)$ were perfused through the rat hindlimb preparation.

emerged concomitantly with ${ }^{125}$ I-labeled bovine serum albumin and reached a steady state level after $\sim 7 \mathrm{ml}$ of perfusion (Fig. 3). The difference between these two curves indicates that $\sim 13.5$ pmol of thrombin must be bound within the vascular tree. The amount of enzyme bound to the membrane cannot be a function of enzyme-inhibitor complex formation with rat antithrombin, since diisofluorophosphate-thrombin (DIP-thrombin) does not displace thrombin from the enzyme-inhibitor complex (25).

To estimate the relative amounts of free and bound thrombin that were neutralized by antithrombin complexed with heparinlike molecules present on the endothelium, $\mathrm{KH}$ buffer containing thrombin (5.4 $\mathrm{nM})$ and DIP-thrombin $(27 \mathrm{nM})$ were perfused through the hindlimb preparation, and the protease inhibitor was infused at a constant level $(0.18 \mu \mathrm{M})$ or injected as a $0.5-\mathrm{ml}$ bolus $(2.7 \mathrm{nmol})$ into the enzyme stream, as outlined above. The effluent from the vena cava was collected as previously described, except that $50 \mathrm{U} / \mathrm{ml}$ of purified hirudin was used in the collecting tubes. Under the above conditions, thrombin cannot bind to the endothelium and is present in solution within the vascular tree at concentrations similar to those observed with the standard perfusion system (data not shown). The average values of thrombin-antithrombin complex formed within the hindlimb preparation in the presence of DIP-thrombin during either constant infusion or bolus injection of the protease inhibitor, when compared with thrombin perfusion in the absence of DIP-thrombin, indicate that the amounts of enzymeinhibitor interaction product are decreased by $30-40 \%$ (Tables II and III).

\section{Discussion}

To examine the role of heparinlike molecules in the regulation of hemostasis, the rat hindlimb was perfused in situ with the human coagulation enzyme, thrombin, and its plasma inhibitor, antithrombin. During the course of our experiments, perfusion of $\mathrm{KH}$ buffer that contained added enzyme did not result in damage to the blood vessels or to its endothelium, as judged by light microscopy that employed Epon-embedded, Giemsastained $1-\mu \mathrm{m}$ sections (22). This histological procedure is particularly suited to detect morphologic changes in blood vessels and its endothelium (26). The validity of this method has been established by electron microscopic studies that were conducted in parallel with the above technique (26).

The fraction of microvessels that were perfused during our studies was estimated by injecting Indian ink into the $\mathrm{KH}$ buffer perfusion stream (23). The vessels counted, according to this procedure, represented terminal arterioles, postcapillary venules, as well as capillaries (23). The percentage of microvessels that were perfused during our experiments, $23.2 \%$, is in reasonable accord with those reported by other investigators (23). The above data indicate that the microvascular bed was patent during perfusion of the hindlimb preparation, and that the coagulation proteins were in contact with the vascular endothelium.

Commercial heparin catalyzes thrombin-antithrombin interactions by inducing a conformational change in the protease inhibitor, which renders the reactive site arginine of this protein more accessible to the active site serine of thrombin (4). The complex sugar is released from antithrombin during enzymeinhibitor complex formation and catalyzes the subsequent generation of interaction product by binding to additional protease inhibitor (4). Thrombin also binds to "approximation" sites that are present on heparin, but this latter interaction is of lesser kinetic consequence for low molecular weight mucopolysaccharide when compared with the antithrombin-heparin interaction $(21,27)$. The mucopolysaccharide also catalyzes the inactivation of coagulation Factors XIIa, XIa, Xa, and IXa via antithrombin in a fashion similar to that described above for thrombin (4).

To determine whether anticoagulantly active heparinlike molecules are present within the vasculature, rat hindlimb preparations were perfused with purified thrombin, and purified antithrombin was either infused at different constant concentrations or injected as a bolus. The amount of thrombin-antithrombin complex formed within the vasculature was estimated by a specific radioimmunoassay for the interaction product. The rate of enzyme-inhibitor complex formation was enhanced as much as 19-fold in the hindlimb vasculature with respect to the uncatalyzed rate of this interaction (Tables I and II). The lower rate of enzyme-inhibitor acceleration observed with the bolus studies and with constant infusion of the protease inhibitor at $1.79 \mu \mathrm{M}$, is due to complexing of virtually all of the thrombin that was perfused under these conditions. Given that the uncatalyzed rate of the thrombin-antithrombin interaction, at the above concentration of protease inhibitor, is $0.86 \mathrm{pmol} / 20 \mathrm{~s}$; the enhancement of complex formation cannot theoretically exceed 4-5-fold after subtraction of the interaction product generated within the cannuli. Furthermore, the acceleration of complex formation under in vivo conditions is much less than that observed under in vitro conditions in the presence of commercial heparin. The lower enhancement of thrombin-antithrombin complex generation observed within the perfused hindlimbs may reflect, in part, either small amounts of heparinlike molecules bound to the surface of the endothelium or a difference in the biologic activity of the species present within the vasculature as compared with mast cell heparin. Indeed, 
our recent studies involving the isolation and characterization of heparinlike molecules from microvasculature indicate that this mucopolysaccharide has a lower specific anticoagulant activity than commercial heparin (14).

The above measurements were performed with a highly sensitive radioimmunoassay for the thrombin-antithrombin complex. This procedure is considerably more specific than classical techniques for measuring the extent of interaction between thrombin and antithrombin, since it directly quantitates enzymeinhibitor complex formation rather than indirectly estimating this molecular species via the residual amount of enzyme activity. Indeed, the latter classical approach cannot completely exclude contributions to thrombin inactivation from blood components other than antithrombin. Furthermore, the radioimmunoassay can quantitate $\sim 30$-fold lower concentration of inhibited enzyme when compared with previously published procedures.

The antithrombin accelerating activity detected in the hindlimb vasculature appears to be due to a heparinlike species based upon the following evidence. A physically homogeneous preparation of Flavobacterium heparinase that did not exhibit proteolytic or chondroitinase activities was recirculated through the hindlimb vasculature before perfusion of the hemostatic components. The amount of enzyme-inhibitor complex generated within the animal was reduced to uncatalyzed levels (Table III). The above data also indicate that it is valid to estimate the uncatalyzed amount of interaction product generated within the hindlimb preparation by utilizing the concentrations of hemostatic components that emerged from the hindquarters and the bimolecular rate constant of this interaction product obtained under in vitro conditions in the absence of heparin. Moreover, these data suggest that the anticoagulantly active mucopolysaccharide is accessible to proteins within the perfusate.

It is of interest to note that addition of $\mathrm{PF}_{4}$ to the antithrombin bolus before injection into the thrombin perfusion stream also reduced the amount of the interaction product formed within the vasculature to uncatalyzed levels. This platelet peptide has been shown to interfere with binding of heparinlike molecules to antithrombin, thereby inhibiting the acceleration of enzymeinhibitor complex formation (8). $\mathrm{PF}_{4}$ also binds to various molecular components, including anticoagulantly inactive heparin (28), chondroitin 4-sulfate $(29,30)$, chondroitin 6-sulfate (29), dermatan sulfate (29), low density lipoprotein receptor (31), collagenase (32), and serotonin (33). Thus, the above data cannot be used to identify heparinlike molecules on the endothelium that can accelerate antithrombin function. However, our findings suggest that $\mathrm{PF}_{4}$, after expulsion from activated platelets, may play a role in thrombogenesis by neutralizing anticoagulantly active mucopolysaccharides that are present on the vascular endothelium.

We next attempted to define the anatomical location of these heparinlike molecules within the hindlimb vasculature. Toward this end, $\mathrm{KH}$ buffer was recirculated through the hindlimb preparation for $30 \mathrm{~min}$, and the perfusate was assayed for mucopolysaccharide by quantitating the extent to which it could accelerate thrombin-antithrombin complex formation. Heparinlike substances were not detected under these conditions (six animals). It should be noted that as little as $3.0 \times 10^{-3} \mathrm{U} / \mathrm{ml}$ of anticoagulantly active heparin could be detected with this methodology. Our findings suggest that heparinlike molecules are not present within the physiologic buffer, but rather that they must be closely associated with the luminal surface of the endothelium.

Indeed, previous investigators have detected heparinlike substances on the luminal surface of the vascular endothelium. Simionescu et al. (34) demonstrated that in situ perfusion of a partially purified preparation of Flavobacterium heparinase specifically removed cationized ferritin-binding sites from the fenestral diaphragms of capillary endothelium. Buonassisi and Root (35) reported that radiolabeled heparinlike molecules were liberated from the surface of cultured bovine aortic endothelial cells with partially purified bacterial heparinase. These investigators, however, did not examine the anticoagulant properties of these heparinlike molecules. Recently, we isolated heparinlike species from retinal microvascular endothelial cell preparations (3). These molecular species accelerated thrombin-antithrombin complex formation, as quantitated by a specific radioimmunoassay for the interaction product. The anticoagulant activity of these mucopolysaccharides was completely destroyed upon incubation with Flavobacterium heparinase. In the current experiments, we could not detect heparinlike molecules within the perfusate, and recirculation of the highly purified mucopolysaccharidase reduced the generation of thrombin-antithrombin complex within the animal to uncatalyzed levels. The above data suggest that these anticoagulantly active mucopolysaccharides are tightly associated with the luminal surface of the endothelium.

Experiments were conducted to determine whether heparinlike molecules that are present on the endothelium function in a fashion similar to commercial heparin. Toward this end, purified antithrombin was chemically modified at tryptophan residue 49 . In the absence of commercial heparin, the altered protease inhibitor inactivates thrombin at a normal rate, whereas the rate of enzyme neutralization is only slightly enhanced in the presence of the mucopolysaccharide. Constant infusion $(0.03$ or $0.09 \mu \mathrm{M})$ or bolus injection $(2.7 \mathrm{nmol})$ of the modified protease inhibitor resulted in a reduction of thrombin-antithrombin complex formation within the hindquarters to uncatalyzed levels (Tables I and II). However, infusion of tryptophan-modified antithrombin at higher concentrations $(0.18 \mu \mathrm{M})$ yielded a slight rate enhancement (2.6-fold) in thrombin-antithrombin complex generation (Table I). This latter finding may reflect the minimal augmentation in the bimolecular rate constant for the thrombinmodified antithrombin interaction product that was observed in the presence of commercial heparin (see above). These observations indicate that a heparinlike substance present on the endothelium enhances thrombin-antithrombin complex formation via a mechanism involving the critical tryptophan residue (No. 49), which is required for heparin-dependent binding and 
for acceleration of the inhibitor. This conclusion is bulwarked by the finding that native and modified antithrombin are able to interact with thrombin at a virtually identical rate under conditions where commercial heparin is absent. Furthermore, our results imply that we have been unable to detect an enhancement of enzyme-inhibitor interactions solely due to binding of thrombin to endothelial sites, as suggested by Lollar et al. $(2,36,37)$.

Lollar and Owen (2) showed that injection of ${ }^{125}$ I-thrombin into the circulatory system of rabbits results in almost immediate complexing of labeled enzyme with antithrombin. They have also reported that DIP-thrombin is able to suppress the neutralization of the enzyme by antithrombin and, on this basis, have claimed that high affinity receptors on the endothelium are responsible for enhancing enzyme-inhibitor interactions. Busch and Owen (38), utilizing protamine sulfate, $\mathrm{PF}_{4}$, and DIP-thrombin, suppressed thrombin-antithrombin complex formation in a Langendorff heart preparation and in cultured endothelial cells. These authors claimed that the above data could be interpreted in terms of endothelial glycosaminoglycans enhancing thrombin-antithrombin complex formation. However, their conclusions are speculative since, as noted earlier, $\mathrm{PF}_{4}$ as well as protamine sulfate bind to various membrane components. In subsequent studies, Lollar et al. (36, 37), employing a recirculating Langendorff heart preparation, confirmed the presence of high affinity thrombin receptors on the vascular endothelium, which catalyze thrombin-antithrombin complex formation. In a recent communication (39), these authors have reported that utilization of antithrombin modified at a single critical tryptophan did not result in an acceleration of thrombinantithrombin complex formation, and have concluded that the high affinity, endothelial receptor responsible for the enhancement of enzyme-inhibitor interaction is not heparin or heparan sulfate.

Based upon the data of Lollar et al. $(36,37)$, we examined the possibility that high affinity thrombin-binding sites may play a role in thrombin neutralization. Toward this end, a fivefold molar excess of DIP-thrombin, which is sufficient to prevent enzyme binding to the endothelium (Fig. 3), was added to thrombin that was perfused through the hindlimb preparation before infusion or injection of antithrombin. The amount of thrombin-antithrombin complex generated in the hindlimb preparation was reduced by only $30-40 \%$ under these conditions (Tables II and III). This phenomenon is most probably due to the saturation of enzyme "approximation" sites on the mucopolysaccharide by DIP-thrombin. These data suggest that thrombin free in the perfusate or bound to the membrane is accessible to protease inhibitor that has interacted with heparinlike molecules present on the endothelium. This is at variance with the findings of Busch and Owen (38), who observed complete abrogation of rapid thrombin inhibition with addition of DIP-thrombin to the perfusion medium of the Langendorff heart preparation. This lack of concordance between the two sets of data indicates that the two acceleratory phenomena may be based upon different molecular mechanisms.

In summary, we have demonstrated that thrombin-antithrombin interactions within the circulatory system are accelerated by heparinlike substances, which are tightly bound to the vasculature. These components appear to "activate" the protease inhibitor in a manner virtually identical to commercial heparin and result in the neutralization of thrombin that is either free within the fluid phase or bound to endothelial sites. Based upon our data, we would propose that a small fraction of the plasma antithrombin is normally bound to heparinlike species associated with the microvascular endothelium. This would permit the protease inhibitor to be selectively activated at blood surface interfaces where enzymes of the intrinsic cascade are commonly generated. Thus, antithrombin would be critically placed to neutralize these enzymes and thereby protect natural surfaces against thrombus formation. The catalytic nature of heparinlike species would ensure the continual regeneration of the nonthrombogenic properties of the endothelial layer. Alterations in this system could result in arterial as well as venous thrombotic disease in humans.

\section{Acknowledgments}

We thank Drs. S. Galli and D. Hill for assistance in preparation of histological specimens.

This work was supported in part by National Institutes of Health grants HL06615, HL25066, and HL28625.

\section{References}

1. Damus, P. S., M. Hicks, and R. D. Rosenberg. 1973. A generalized view of heparin's anticoagulant action. Nature (Lond.). 246:355-357.

2. Lollar, P., and W. G. Owen. 1980. Clearance of thrombin from the circulation in rabbits by high-affinity binding sites on the endothelium: possible role in the inactivation of thrombin by antithrombin III. $J$. Clin. Invest. 66:1222-1230.

3. Marcum, J. A., L. Fritze, S. J. Galli, G. Karp, and R. D. Rosenberg. 1983. Microvascular heparinlike species with anticoagulant activity. Am. J. Physiol. 245:H725-H733.

4. Rosenberg, R. D., K. A. Bauer, and J. A. Marcum. 1984. The heparin-antithrombin system. In Reviews in Hematology. E. Murano, editor. P.J.D. Publications, Ltd. Westbury, New York. In press.

5. Ruderman, N. B., C. R. S. Houghton, and R. Hems. 1971. Evaluation of the isolated rat hindquarter for the study of muscle metabolism. Biochem. J. 124:639-651.

6. Rosenberg, J. S., D. L. Beeler, and R. D. Rosenberg. 1975. The activation of human prothrombin by purified human factor $\mathrm{V}$ and factor $\mathrm{Xa}$ in the presence of human antithrombin. J. Biol. Chem. 250:16071617.

7. Blackburn, M. N., and C. C. Sibley. 1980 . The heparin binding site of antithrombin III. J. Biol. Chem. 255:824-826.

8. Jordan, R. E., L. V. Favreau, E. H. Braswell, and R. D. Rosenberg. 1982. Heparin with two binding sites for antithrombin or Platelet factor 4. J. Biol. Chem. 257:400-406.

9. Linker, A., and P. Hovingh. 1972. Heparinase and heparitinase from Flavobacteria. Methods Enzymol. 28:902-911.

10. Castellot, J. J., Jr., M. L. Addonizo, R. D. Rosenberg, and 
M. J. Karnovsky. 1981. Cultured endothelial cells produce a heparinlike inhibitor of smooth muscle cell growth. J. Cell Biol. 90:372-379.

11. O'Farrell, P., H. M. Goodman, and P. H. O'Farrell. 1977. High resolution two-dimensional electrophoresis of basic as well as acidic proteins. Cell. 12:1133-1142.

12. Galliher, P. M., C. L. Cooney, R. Langer, and R. J. Lindhardt. 1981. Heparinase production by Flavobacterium heparinum. Appl. Environ. Micro. 41:360-365.

13. Highsmith, R. F., and R. D. Rosenberg. 1977. A rapid and sensitive proteolytic assay for human plasminogen and plasmin using radioiodinated alpha-casein. Thromb. Res. 11:131-140.

14. Marcum, J. A., and R. D. Rosenberg. 1984. Anticoagulantly active heparinlike molecules from vascular tissue. Biochemistry. 33:17301737.

15. Lowry, O. H., N. J. Rosebrough, A. L. Farr, and R. J. Randall. 1951. Protein measurement with the folin phenol reagent. J. Biol. Chem. 193:265-275.

16. Lau, H. K., and R. D. Rosenberg. 1980. The isolation and characterization of a specific antibody population directed against the thrombin-antithrombin complex. J. Biol. Chem. 255:5885-5893.

17. Bauer, K. A., J. B. Ashenhurst, J. Chediak, and R. D. Rosenberg. 1984. Antithrombin "Chicago": a functionally abnormal molecule with increased heparin affinity causing familial thrombophilia. Blood. 62:12421250.

18. Rodbard, D. 1974. Statistical quality control and routine data processing for radioimmunoassays and immunoradiometric assays. Clin. Chem. 20:1255-1270.

19. Rodbard, D., R. H. Lenox, H. L. Wray, and D. Ramseth. 1976. Statistical characterization of the random errors in the radioimmunoassay dose-response variable. Clin. Chem. 22:350-358.

20. Zar, J. H. 1974. Biostatistical Analysis. Prentice-Hall Inc., New York. 181-224.

21. Jordan, E. E., G. M. Oosta, W. T. Gardner, and R. D. Rosenberg 1980. The kinetics of interaction of low molecular weight heparin and antithrombin with factor IXa, factor Xa, plasmin, and thrombin. $J$. Biol. Chem. 255:10081-10090.

22. Dvorak, H. F., M. E. Hammond, R. B. Colvin, E. J. Manseau, and J. Goodwin. 1977. Systemic expression of cutaneous basophil hypersensitivity. J. Immunol. 118:1549-1557.

23. Renkin, E. M., S. D. Gray, and L. R. Dodd. 1981. Filling of microcirculation in skeletal muscles during timed Indian ink perfusion Am. J. Physiol. 241:H174-H186.

24. Awbrey, B. J., J. C. Hoak, and W. G. Owen. 1979. Binding of human thrombin to cultured human endothelial cells. J. Biol. Chem. 254:4092-4095.

25. Rosenberg, R. D., and P. S. Damus. 1973. The purification and mechanism of action of human antithrombin-heparin cofactor. J. Biol. Chem. 248:6490-6505.

26. Galli, S. J., R. C. Blast, B. S. Blast, T. Isomura, B. Zbar, H. J.
Rapp, and H. F. Dvorak. 1982. Bystander suppression of tumor growth: evidence that specific targets and bystanders are damaged by injury to a common microvasculature. J. Immunol. 129:1790-1799.

27. Jordan, R. E., G. M. Oosta, W. T. Gardner, and R. D. Rosenberg. 1980. The kinetics of hemostatic enzyme-antithrombin interactions in the presence of low molecular weight heparin. J. Biol. Chem. 255:1007310080.

28. Niewiarowski, S., B. Rucinski, P. James, and U. Lindahl. 1979. Platelet antiheparin proteins and antithrombin III interact with different binding sites on heparin molecule. FEBS (Fed. Eur. Biochem. Soc.) Lett. 102:75-78.

29. Barber, A. J., R. Kaeser-Glausmann, M. Jakaboua, and E. F. Lusher. 1972. Characterization of a chondroitin 4-sulfate proteoglycan carrier for heparin neutralizing activity (platelet factor 4) released from human platelets. Biochim. Biophys. Acta. 286:312-329.

30. Huang, S. S., J. S. Huang, and T. F. Deuel. 1982. Proteoglycan carrier of human platelet factor 4: isolation and characterization. J. Biol. Chem. 257:11546-11550.

31. Brown, M. S., T. F. Deuel, S. K. Basu, and J. L. Goldstein 1978. Inhibition of the binding of low density lipoprotein to its cell surface receptor in human fibroblasts by positively charged proteins. $J$. Supramol. Struct. 8:223-234.

32. Harper, J., H. Wohl, and E. Harper. 1978. Platelet factor 4 an inhibitor of collagenase. Science (Wash. DC). 199:991-992.

33. Heemstra, V. L. 1983. Evidence for serotonin binding in vitro by platelet factor 4 and beat thrombo globulin. Thromb. Res. 29:323332.

34. Simionescu, M., N. Simionescu, J. E. Silbert, and G. E. Palade. 1981. Differentiated microdomains on the luminal surface of the capillary endothelium. II. Partial characterization of their anionic sites. J. Cell. Biol. 90:614-621.

35. Buonassisi, V., and M. Root. 1975. Enzyme degradation of heparin-related mucopolysaccharides from the surface of the endothelial cell cultures. Biochim. Biophys. Acta. 385:1-10.

36. Lollar, P., S. MacIntosh, and W. G. Owen. 1982. Interaction of thrombin with the vascular endothelium in a recirculating Langendorff rabbit heart preparation. Ann. NY Acad. Sci. 401:234-240.

37. Lollar, P., S. M. Hale, and W. G. Owen. 1982. Interaction of thrombin with the vascular endothelium in a recirculating Langendorff rabbit preparation. Circulation. 66:II-53.

38. Busch, C., and W. G. Owen. 1982. Identification in vitro of an endothelial cell surface cofactor for antithrombin III: parallel studies with isolated perfused rat hearts and microcarrier cultures of bovine endothelium. J. Clin. Invest. 69:726-729.

39. Lollar, P., S. C. MacIntosh, and W. G. Owen. 1984. Reaction of antithrombin III with thrombin bound to the vascular endothelium: analysis in a recirculating perfused rabbit heart preparation. J. Biol. Chem. 259:4335-4338. 